\title{
Are we Teaching our Machines our Biases, Presumptions and Stereotypes?
}

\author{
Jutta Treviranus* \\ Inclusive Design Research Centre, OCAD University, Canada
}

Submission: April 14, 2017; Published: May 05, 2017

*Corresponding author: Jutta Treviranus, Inclusive Design Research Centre, OCAD University, 100 McCaul Street, Toronto, Ontario Canada, Email: jtreviranus@ocadu.ca

\section{Opinion}

Artificial intelligence has been heralded as a promising assistive technology to provide greater independence and security for individuals with intellectual disabilities. Scenarios have been envisioned in which intelligent machines act as personal assistants or companions to remind, prompt, guide, and alert to risk. The popular press and entertainment media is rife with speculations regarding the implications of advancing artificial intelligence (AI). Imagined futures range from: escalating unemployment as robots and self-driving vehicles replace workers, humanoid robots that act as indistinguishable community members or servants, cyborg enhancements of our flawed human forms, smart environments that anticipate and serve our every wish, to machine intelligence that takes over the world from inferior humans $[1,2]$.

Artificial intelligence is not an "imminent reality." It already pervades our everyday life in subtle and habituated ways. It is making increasingly important decisions for us, controlling what we are exposed to, manipulating our attention, providing advice, guiding our travel, and reducing drudgery. Whether in the form of online mortgage and loan approval, learning management systems with learning analytics that determine what and how students learn, our browser search engines, the health help-line we call in the middle of the night for health advice, the database that prepares our legal case, the GPS we use to find our way, or the human resources application that filters, sorts and ranks applications; artificial intelligence is inextricably woven into our society and daily lives $[3,4]$.

It has been claimed that machine intelligence is more objective, thorough, and less likely to make mistakes. The lack of emotional reaction or bias is referenced as strength of machine-guided decisions. The claim is that algorithmically determined findings are impartial and just, blindly following the established rules. The contention that the algorithms can be independent of the data and thereby uncontaminated by biased influence is challenged by ethicists and others concerned with the amplifying effect of connected technologies. They point out that the algorithms are engineered by humans, and increasingly complex and opaque. Whether seen as an opportunity or a threat, all experts agree that the quickly escalating role of machine intelligence is inevitable. Like all disruptive changes, this has important implications for people with disabilities, or anyone at the margins of our society that is less buffered from collateral effects.

Before an intelligent machine can be of help, it has to understand us. There is nothing more frustrating than negotiating with a machine that does not recognize our request or that misunderstands our command. Machine intelligence is formed by machine learning engines using training data. A variety of learning processes (whether supervised or unsupervised by humans) are employed to use data to create models from which the intelligent machines recognize patterns, formulate inferences and make decisions. Accuracy is honed through feedback processes that identify and correct mistakes. The emergence of "Big Data" and connected sensors and monitors (e.g., smart phones, health and fitness monitors, security cameras, bio-sensors, connected vehicles, etc.) feed this machine learning: creating intelligence that is more comprehensive and detailed than ever before. Privacy is a value that has been irretrievably sacrificed in the process.

"Big Data" inherits methods from quantitative, statistics-based research. Data is "cleaned" and normed and thereby reduced to find dominant patterns and generalizable findings. This implies eliminating "noise" or outlying data that is assumed to be an anomaly that could muddy the conclusions. This data is used to recognize speech, faces, illnesses, or to predict loan and credit worthiness, academic potential, terrorists and future employment performance.

Whether we hope to use machines as assistive technologies or are worried about the fit or accessibility of machine-powered services, the data used to train machines should be of interest. People with disabilities are, by definition, different from the norm. 
This difference, especially extreme difference, is predominantly treated as outlying data to be eliminated in the process of efficiently finding dominant patterns from which to make inferences.

The effect of this data handling can be felt in the failure to recognize impaired speech, process unusual requests, diagnose complicated illnesses, accept unusual applications, or give security access through unexpected biometrics. As machine intelligence permeates our daily lives, this effect will drive a larger wedge of disparity between those that are served and those that are not understood, recognized or served. The most pessimistic scenario is an exponentially amplified vicious cycle of exclusion for individuals already at the margins.

There is a hopeful thread in this entangled and complex inevitability. As with all wisdom gained and substantiated by supporting precarious values such as accessibility and inclusion, we find that considering the edge benefits everyone. While it is more expedient to move quickly to dominant patterns, if we learn from edge scenarios and develop our intelligence by exposure and understanding of diversity and difference we gain in the long run. Intelligence that understands diversity and stretches to encompass the outliers is more noise tolerant, better at predicting risk and opportunity, more capable of processing the unexpected, more adaptable, and more dynamically resilient.

Whether we welcome or fear machine intelligence, it is important that we attend to what we teach machines. Do our machines understand and serve individuals that are different or fail to recognize and ignore anyone that does not conform to the model of an average human?.

\section{References}

1. den Brok WL, Sterkenburg PS (2015) Self-controlled technologies to support skill attainment in persons with an autism spectrum disorder and/or an intellectual disability: a systematic literature review. Disabil Rehabil Assist Technol 10(1): 1-10.

2. Gary Marcus (2013) why should we think about the threat of artificial intelligence. The new yorker, USA.

3. Ben Lorica (2017) 7 AI trends to watch in 2017. o'Reilly Media, USA.

4. Feigenbaum EA (1977) the art of artificial intelligence: 1. Themes and case studies of knowledge engineering. Stanford Univ USA, p. 1-20.

\section{Your next submission with Juniper Publishers will reach you the below assets}

- Quality Editorial service

- Swift Peer Review

- Reprints availability

- E-prints Service

- Manuscript Podcast for convenient understanding

- Global attainment for your research

- Manuscript accessibility in different formats

( Pdf, E-pub, Full Text, Audio)

- Unceasing customer service

Track the below URL for one-step submission https://juniperpublishers.com/online-submission.php 